\title{
Machining Accuracy of Crowns by CAD/CAM System Using TCP/IP : Influence of Restorative Material and Scanning Condition
}

\author{
Sachiko TOMITA ${ }^{1}$, Akiyoshi SHIN-YA ${ }^{1}$, Harunori GOMI ${ }^{1}$, Akikazu SHIN-YA ${ }^{1,2}$ and Daiichiro YOKOYAMA ${ }^{1}$ \\ ${ }^{1}$ Department of Crown and Bridge, School of Life Dentistry at Tokyo, The Nippon Dental University, 1-9-20 Fujimi, \\ Chiyoda-ku, Tokyo 102-8159, Japan \\ ${ }^{2}$ Department of Prosthetic Dentistry and Biomaterials Science, Institute of Dentistry, University of Turku, Lemminkä \\ isenkatu 220520 Turku, Finland \\ Corresponding author, Akiyoshi SHIN-YA; E-mail: Shinya-a@tky.ndu.ac.jp
}

Received June 7, 2006/Accepted March 14, 2007

The purpose of this study was to determine the optimal condition for fabricating accurate crowns efficiently using an internet-based CAD/CAM system. The influences of three different CAD/CAM restorative materials (titanium, porcelain, and composite resin) and three different step-over scanning distances $(0.01 \mathrm{~mm}, 0.11 \mathrm{~mm}$, and $0.21 \mathrm{~mm})$ were evaluated, and their interactive effects were carefully examined.

Several points on the inner and outer surfaces of machined crowns - as well as height — were measured. These measurements were then compared with the original models, from which machining accuracy was obtained. At all measuring points, the inner surface of all crowns was machined larger than the die model, whereas the cervical area of porcelain crown was machined smaller than the crown model. Results of this study revealed that a step-over distance of $0.11 \mathrm{~mm}$ was an optimal scanning condition, taking into consideration the interactive effects of scanning time required, data volume, and machining accuracy.

Keywords: TCP/IP, CAD/CAM, Machining accuracy

\section{INTRODUCTION}

The introduction of dental CAD/CAM systems has brought about many benefits such as high-quality dental restorations ${ }^{1,2)}$, standardized machining accuracy $^{3.5)}$, streamlined design and fabrication processes $^{6,7}$, and improved laboratory environments ${ }^{8.11}$. With the development of internet technology, internet-based CAD/CAM systems have gained much attention and attracted much interest lately. In this setup, a scanning unit and a computer loaded with CAD software are installed at the dental office and connected with a CAM processing center via internet.

For dental technicians working at the centralized processing centers, they could fabricate accurate dental prostheses only with digitized information transmitted from the dental offices. On this note, one factor that affects scanning accuracy is the step-over scanning distance, which defines the distance between neighboring scanning strips. Scanning accuracy increases with smaller step-over distance. However, this would mean greater data volume as well as longer data processing time. Thus, determination of the optimal scanning condition would entail the combination of different factors.

The aim of this research was to determine the effects of step-over and CAD/CAM restorative material on machining accuracy. Models were scanned with three different scanning conditions (i.e., step-over distances of $0.01 \mathrm{~mm}, 0.11 \mathrm{~mm}$, and 0.21 $\mathrm{mm})$. Each of the three restorative materials namely, titanium, porcelain, and composite resin crowns - were then machined with each scanning condition. Machining accuracy was obtained by measuring the deviation between a machined crown and the original model.

\section{MATERIALS AND METHODS}

\section{Materials}

Three kinds of CAD/CAM restorative materials, titanium blocks (Ti) (JIS II H4650; Advance Co. Ltd., Tokyo Japan), porcelain blocks (Po) (Cadim Porcelain; Advance Co. Ltd., Tokyo Japan), and resin blocks (HR) (GC composite resin; GC Corp., Tokyo Japan) were used for this test. Tables 1 and 2 show the compositions and mechanical properties of the CAD/CAM restorative materials used in this study, respectively.

\section{Methods}

To investigate the influences of different CAD/CAM restorative materials and scanning conditions on the machining accuracy of inner and outer surfaces of crowns, experiments were carried out with different experimental factors and combinations. Data obtained were then analyzed using two-way analysis of variance (ANOVA).

Three kinds of CAD/CAM restorative materials $\mathrm{Ti}, \mathrm{Po}$, and HR - were prepared for factor A, and three step-over scanning distances of $0.01 \mathrm{~mm}, 0.11$ 
$\mathrm{mm}$, and $0.21 \mathrm{~mm}$ (St0.01, St0.11, St0.21) were prepared for factor $B$.

Shapes of the die and crown models were scanned. Captured and manipulated scanning data were transmitted to the processing center via internet, where crowns were fabricated. Machining processes with combinations of factor $\mathrm{A}$ and factor $\mathrm{B}$ were repeated three times, so that a total of 27 crowns were fabricated.

\section{Specimen fabrication}

1. The die model and crown model

Figure 1 shows a schematic illustration of the die and crown models (SUS-304), as well as their dimensions. Dimensions of the die model were as follows: base diameter $(\varphi 9.0 \mathrm{~mm})$, occlusal surface $(\varphi 6.0 \mathrm{~mm})$, height $(6.0 \mathrm{~mm}), 8$-degree taper, and a round form of

Table 1 Compositions of CAD/CAM restorative materials

\begin{tabular}{ll}
\hline Code & Compositions \\
\hline $\mathrm{Ti}:$ & $\mathrm{Ti}:$ Balance, O: $0.20 \%, \mathrm{Fe}: 0.25 \%, \mathrm{~N}: 0.05 \%, \mathrm{H}: 0.02 \%$ \\
$\mathrm{Po}:$ & $\mathrm{SiO}_{2}: 55 \sim 65 \%, \mathrm{Al}_{3} \mathrm{O}_{3}:$ 15 25\%, $\mathrm{Na}_{2} \mathrm{O}: 6 \sim 8 \%, \mathrm{~K}_{2} \mathrm{O}: 6 \sim 8 \%$ \\
$\mathrm{HR}:$ & Fine particle of silica: $60 \%$, Uretangemetacrirat: $40 \%$ \\
\hline
\end{tabular}

$0.5 \mathrm{~mm}$ radius was prepared at both the cervical contour and axial-occlusal line angle.

Dimensions of the corresponding crown model were as follows: base diameter $(\varphi 9.0 \mathrm{~mm})$, occlusal surface $(\varphi 8.0 \mathrm{~mm})$, height $(7.0 \mathrm{~mm})$, 8-degree taper, and a round form of $0.5 \mathrm{~mm}$ radius was prepared at the axial-occlusal line angle.

\section{CAD/CAM system}

Internet-based CAD (Dental Cadim 107D, Advance Co. Ltd., Tokyo Japan) was used in this study (Fig. 2). Cadim consisted of a scanning unit - whereby scanning was done with contact analog method, and a personal computer loaded with a CAD software (Tracecut 24, Renishaw Plc., UK). Table 3 gives the specifications of Cadim.

\section{Scanning}

After mounting the die model on Cadim Setting Plate using a dental stone (New Fujirock, GC Corp., Tokyo, Japan), it was installed on the scanning area of the unit (Fig. 3).

First, the cervical area of die model was scanned with 2D X-Y scanning, from which scanning range for 3D scanning was defined. Shape of the die model was scanned radially with a 3D contact scanning method based on the defined scanning range, thus

Table 2 Mechanical properties of $\mathrm{CAD} / \mathrm{CAM}$ restorative materials

\begin{tabular}{lcccc}
\hline & & $\mathrm{Ti}$ & Po & HR \\
\hline Hardness & $(\mathrm{HV})$ & 110 & $552 \pm 27$ & 388 \\
Density & $\left(\mathrm{g} / \mathrm{cm}^{3}\right)$ & 4.51 & & $1.62 \pm 0.01$ \\
Compressive strength & $(\mathrm{MPa})$ & & 617 & $595 \pm 24$ \\
Bending strength & $(\mathrm{MPa})$ & & 95 & $190 \pm 15$ \\
Proofstress & $(\mathrm{MPa})$ & 215 & & \\
Elongation & $(\%)$ & 23 & & \\
Tensile strength & $(\mathrm{MPa})$ & $340 \sim 510$ & & $49 \pm 00$ \\
Modulus of clasticity & $(\mathrm{MPa})$ & & & 60 \\
Filler particle content & $(\mathrm{wt} \%)$ & & $8.3 \sim 9.6 \times 10.6$ & \\
Modul us of thermal expansion & $(1 / \mathrm{K})$ & & & \\
\hline
\end{tabular}

used the manufacturer's official data
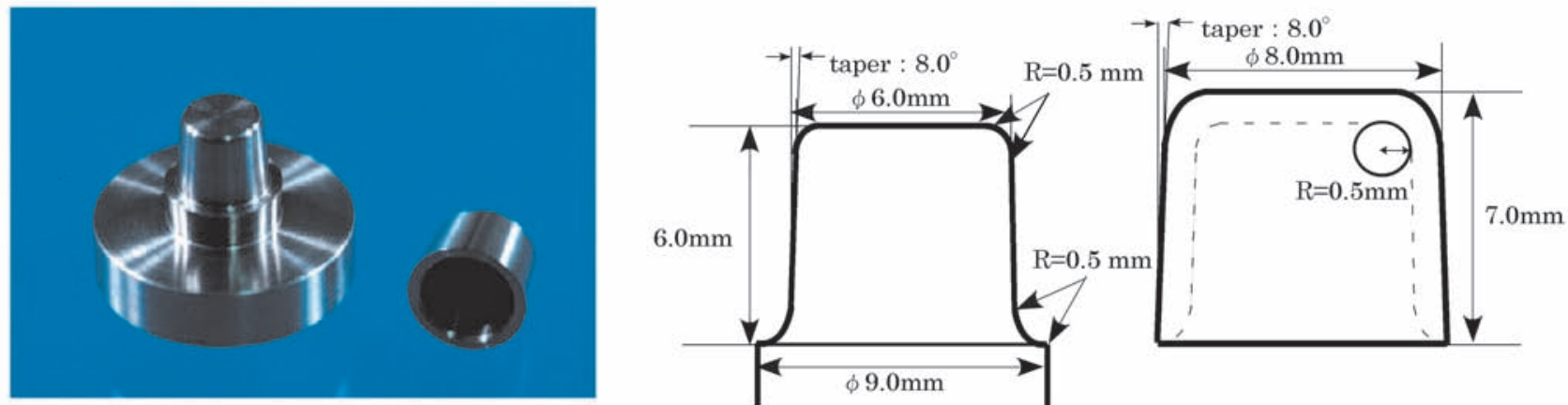

The die model

The crown model

Fig. 1 Schematic illustration of the die and crown models and their dimensions. 


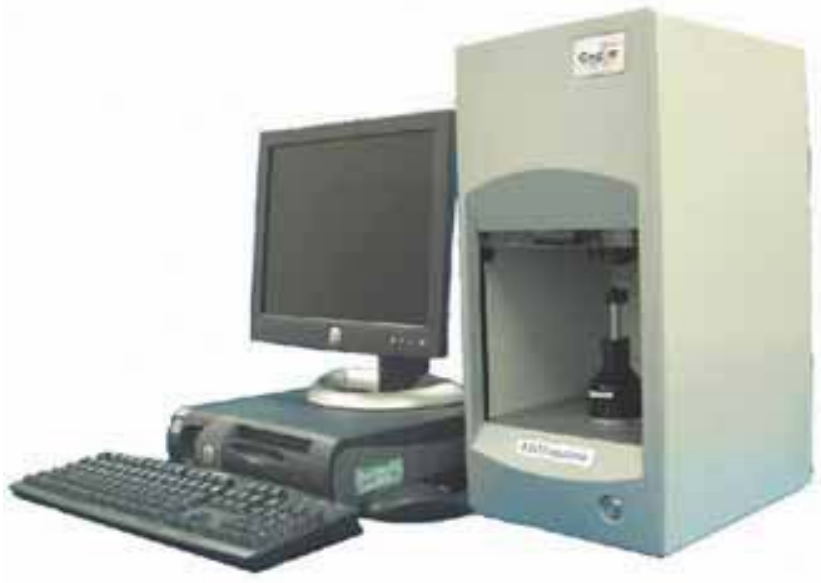

Fig. 2 Dental Cadim 107D.

Table 3 Specifications of Cadim

\begin{tabular}{|c|c|}
\hline \multicolumn{2}{|l|}{ Scanning unit } \\
\hline Range & $\varphi 90 \times 45 \mathrm{~mm}$ \\
\hline Probe deflectoin & $18 \sim 30 \mathrm{~g}$ \\
\hline Probe resolution & $1 / 1000 \mathrm{~mm}$ \\
\hline Overall siza & W245x D315× H505 mm \\
\hline Weight & $13 \mathrm{Kg}$ \\
\hline \multirow[t]{2}{*}{$\mathrm{PC}$} & Desktop PC \\
\hline & Windows 2000 \\
\hline Software & Tracecut 24 \\
\hline
\end{tabular}

capturing 2D and 3D data. Shape of the crown model, having been mounted on the die, was scanned in the same manner as the die model (Fig. 4).

As for the scanning condition, three different step-over distances $(0.01,0.11,0.21 \mathrm{~mm})$ were used in this study. Tests were carried out for each scanning condition. With the exception of step-over, other scanning parameters were the same for all the tests as follows:

Scanning speed: $1000 \mathrm{~mm} / \mathrm{min}$;

Scanning pitch (die model): $0.05 \mathrm{~mm}$;

Scanning pitch (crown model): $0.1 \mathrm{~mm}$;

Probe deflection: $30 \mathrm{~g}$;

Scanning direction: Two-way.

$2 \mathrm{D}$ and $3 \mathrm{D}$ data were captured by positioning a stylus of $\varphi 1 \mathrm{~mm}$ and made of cylindrical tungsten carbide bur in contact with the models. Digitized crown shape was generated by combining captured $3 \mathrm{D}$ die data with captured 3D crown data on the screen. The photographs of Fig. 5 represent the captured scanning data of both die and crown models with each step-over distance. The time durations required for scanning the die and crown models with

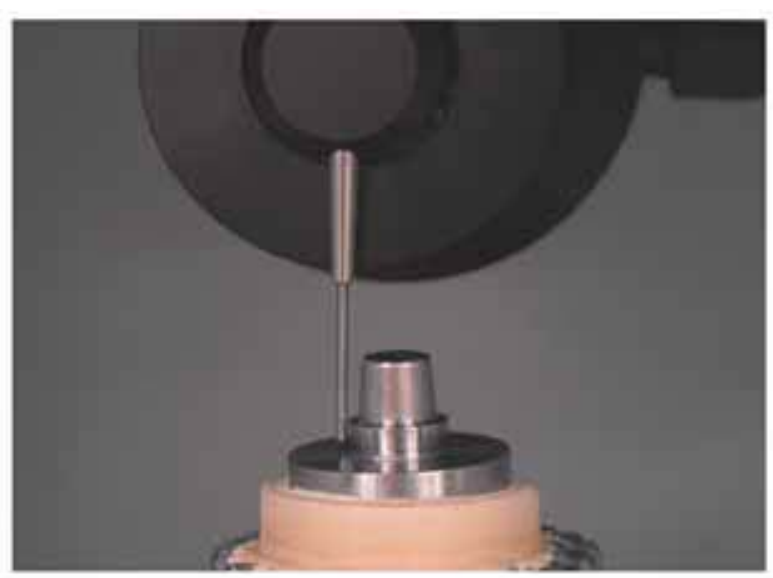

Fig. 3 Scanning of the die model.

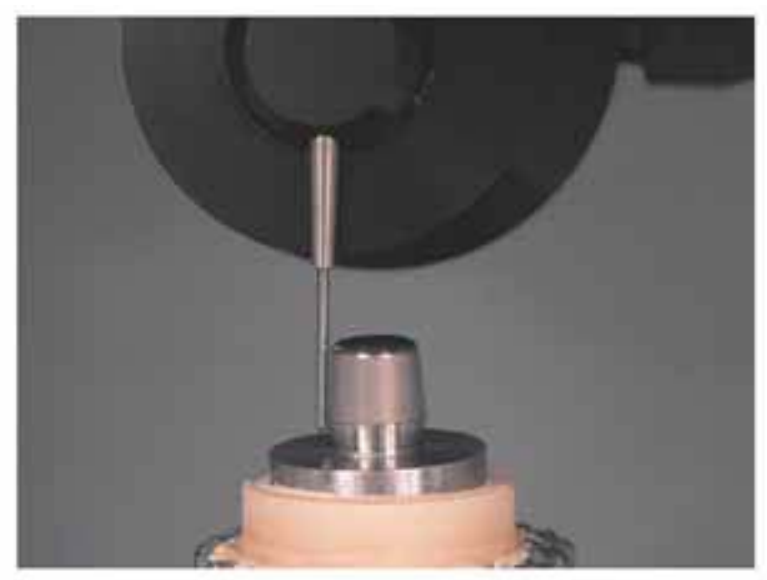

Fig. 4 Scanning of the crown model.

Table 4 Time durations required for scanning the die and crown models with each scanning condition

\begin{tabular}{ccc}
\hline step-over & die model & crown model \\
\hline 0.01 & 175 & 183 \\
0.11 & 18 & 35 \\
0.21 & 9 & 10 \\
\hline
\end{tabular}

step-over distance $(\mathrm{mm})$ die and crown mode(min)

each scanning condition are shown in Table 4.

4. Data transmission

Digitized data was compressed into LZH format and transmitted to the processing center using Cadim Software (Advance Co. Ltd., Tokyo Japan). Data volumes required were 11.8 MB (St0.01), $957 \mathrm{~KB}$ (St0.11), and $500 \mathrm{~KB}$ (St0.21).

5. Machining process

At the processing center, NC cutter paths and CAD output files were generated based on the transmitted digitized data. Table 5 shows the machining parameters for Ti, while Table 6 shows the machining 


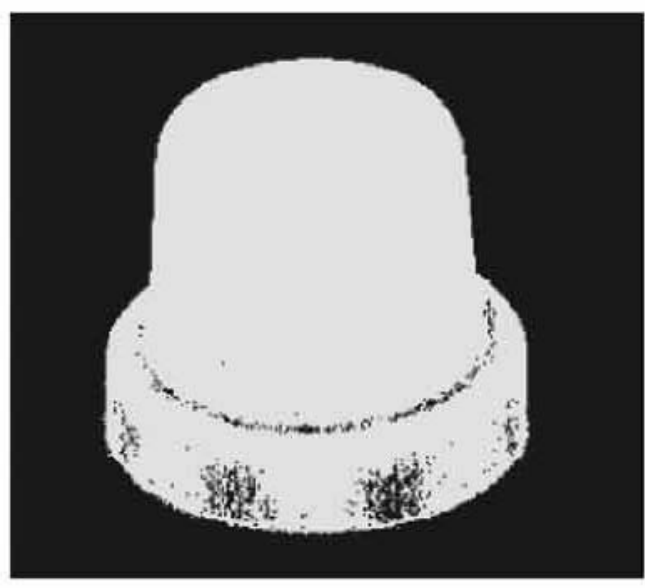

St0.01

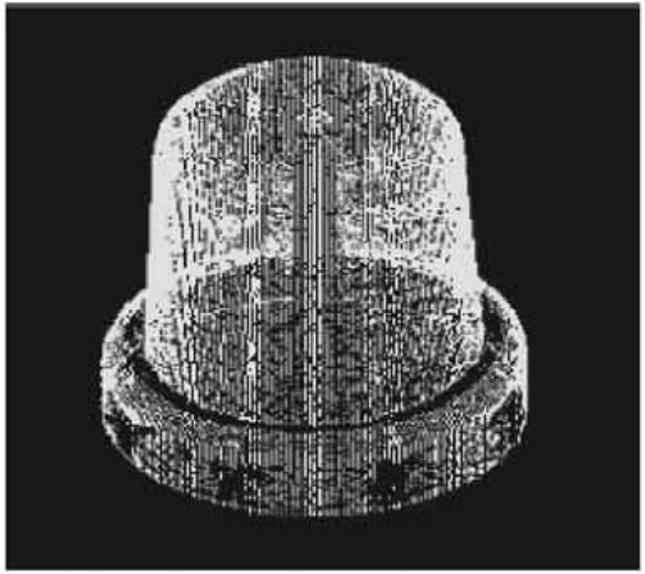

St0.11

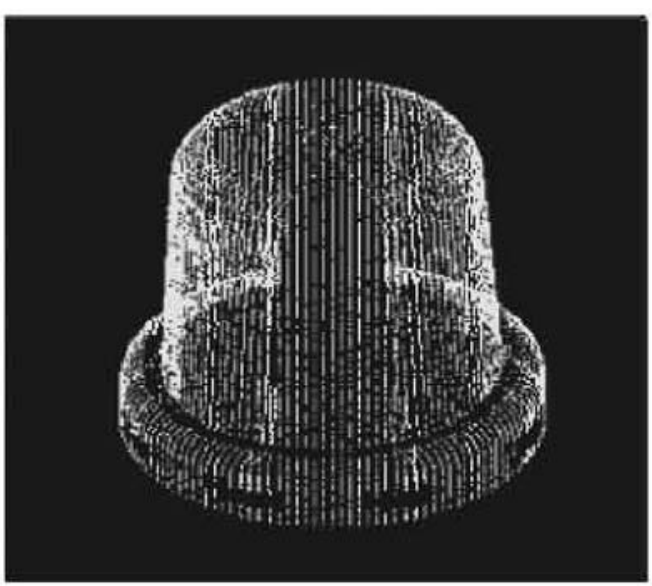

St0.21

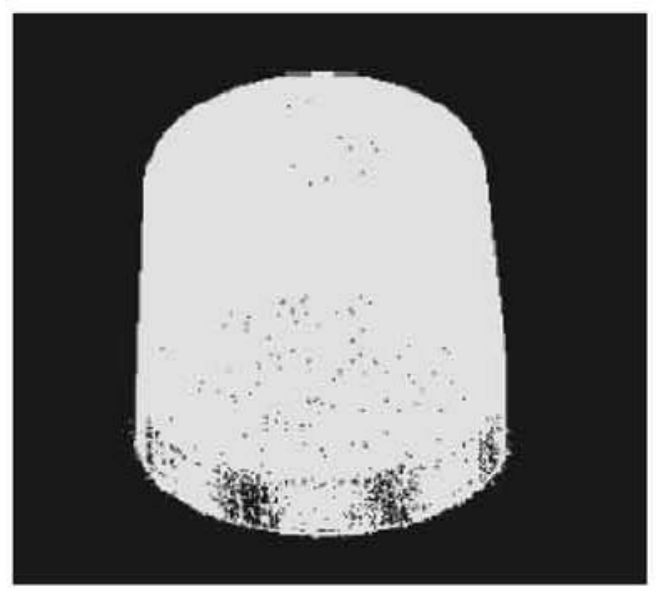

St0.01

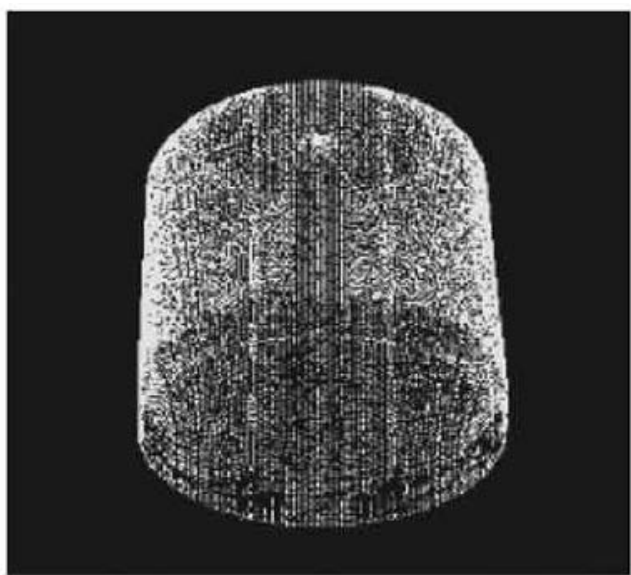

St0.11

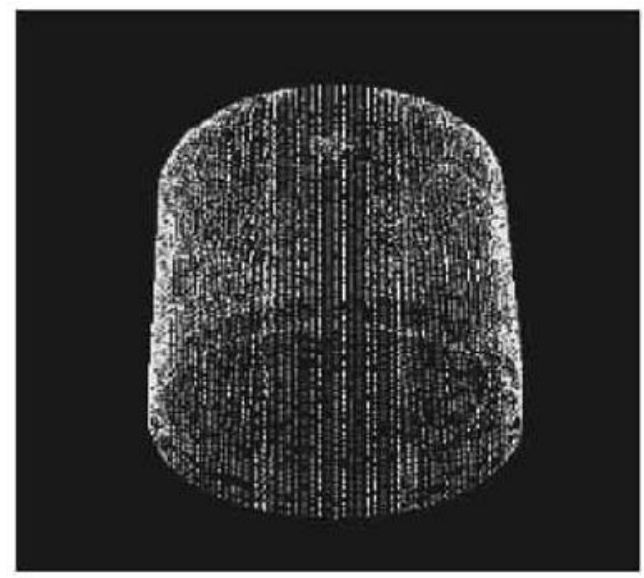

St0.21

Fig. 5 Captured scanning date of the die and crown models scanned with St0.01, St0.11, St0.21. 
Table 5 Machining parameters of $\mathrm{Ti}$

\begin{tabular}{|c|c|c|c|c|c|}
\hline & \multicolumn{3}{|c|}{ Inner surface } & \multicolumn{2}{|c|}{ Outer surface } \\
\hline & $\begin{array}{l}\text { Coarse } \\
\text { machining }\end{array}$ & $\begin{array}{l}\text { Medium } \\
\text { machining }\end{array}$ & Finishing & $\begin{array}{l}\text { Coarse } \\
\text { machining }\end{array}$ & Finishing \\
\hline Tool diameter (mm) & 2 & 2 & 1 & 2 & 1 \\
\hline Feedrate XY (mm/min) & 1000 & 400 & 318 & 1000 & 250 \\
\hline Feedrate $\mathrm{Z}$ down $(\mathrm{mm} / \mathrm{min})$ & 500 & 200 & 318 & 500 & 150 \\
\hline Feedrate $\mathrm{Z}$ up (mm/min) & 1500 & 500 & 318 & 1500 & 200 \\
\hline Machining method & Terrace & Terrace & Redial & Terrace & Radial \\
\hline Type of cut & Clear & Finish & Finish & Clear & Finish \\
\hline Surface of fset (mm) & 0.1 & 0 & 0 & 0.1 & 0 \\
\hline Machining derection & $\begin{array}{l}\text { Rectangular } \\
\text { Spiral }\end{array}$ & $\begin{array}{l}\text { Rectangular } \\
\text { Spiral }\end{array}$ & One way & $\begin{array}{l}\text { Rectangular } \\
\text { Spiral }\end{array}$ & Two way \\
\hline
\end{tabular}

Table 6 Machining parameters of Po and HR

\begin{tabular}{|c|c|c|c|c|c|c|c|}
\hline & \multicolumn{5}{|c|}{ Inner surface } & \multicolumn{2}{|c|}{ Outer surface } \\
\hline & $\begin{array}{l}\text { Coarse } \\
\text { machining }\end{array}$ & $\begin{array}{l}\text { Medium } \\
\text { machining }\end{array}$ & Finishing & $\begin{array}{l}\text { Margin } \\
\text { finishingl }\end{array}$ & $\begin{array}{l}\text { Margin } \\
\text { finishing } 2\end{array}$ & $\begin{array}{l}\text { Coarse } \\
\text { machinig }\end{array}$ & Finishing \\
\hline Tool diameter $(\mathrm{mm})$ & 2 & 2 & 2 & 1 & 1 & 2 & 2 \\
\hline Feedrate XY (mm/min) & 300 & 300 & 300 & 300 & 300 & 300 & 300 \\
\hline Feedrate $\mathrm{Z}$ down $(\mathrm{mm} / \mathrm{min})$ & 250 & 250 & 100 & 200 & 200 & 250 & 200 \\
\hline Feedrate $\mathrm{Z}$ up $(\mathrm{mm} / \mathrm{min})$ & 1000 & 1000 & 200 & 300 & 300 & 1000 & 300 \\
\hline Machining method & Terrace & Terrace & Radial & Terrace & Radial & Terrace & Radial \\
\hline Type of cut & Clear & Finish & Finish & Finish & Finish & Clear & Finish \\
\hline Surface offset (mm) & 0.05 & 0 & 0 & 0 & 0 & 0.05 & 0 \\
\hline Machining derection & $\begin{array}{l}\text { Rectangular } \\
\text { Spiral }\end{array}$ & $\begin{array}{l}\text { Rectangular } \\
\text { Spiral }\end{array}$ & Two way & $\begin{array}{l}\text { Rectangular } \\
\text { Spiral }\end{array}$ & Two way & $\begin{array}{l}\text { Rectangular } \\
\text { Spiral }\end{array}$ & Two way \\
\hline
\end{tabular}

parameters for $\mathrm{Po}$ and HR. As for cement space, a luting cement film thickness of $50 \mu \mathrm{m}$ was set at $1 \mathrm{~mm}$ above the margin line, and it gradually decreased to $0 \mathrm{~mm}$ at margin line.

Measurement of CAD/CAM crown using $3 D$ coordinate measuring machine

1. Measuring machine

Inner and outer surfaces of machined crowns were measured using a 3D coordinate measuring machine (E-DC-M400, Tokyo Seimitsu Co. Ltd. Japan), which consisted of three main components: the machine itself, a computer-controlled system (Type 2400-WBB $\mathrm{S} / \mathrm{N} 97-\mathrm{A} 0231$, IBM), and a measurement software (40 series, all-purpose measuring program XYZAX).

Measurements were carried out using a probe (TP1, Renishaw Inc.) with a 1-mm-radius stylus. Measurement parameters were as follows: horizontal probe deflection (15 gf,), vertical probe deflection (25 gf). Thus, a measurement accuracy of less than $\pm 2.0 \mu \mathrm{m}$ was obtained. Ambient operating temperature was $23.0 \pm 2.0^{\circ} \mathrm{C}$, humidity was $50 \pm 5 \%$.

\section{Baseline setup}

Setup of the baseline and measuring points were carried out in accordance with those of Konishi ${ }^{12)}$. Inner occlusal was aligned with X-Y plane of the machine and defined as the baseline. Twelve random points on the circumference of the inner surface of CAD/CAM crown were measured $5.0 \mathrm{~mm}$ away from the baseline in Z-direction, and from which the central coordinates of the circle were computed.

Similarly, outer occlusal was defined as the baseline. As such, 12 random points on the circumference of the outer surface of CAD/CAM crown were measured $6.0 \mathrm{~mm}$ away from the baseline in $\mathrm{Z}$ direction, and from which the central coordinates of the circle were also computed. Central axis was established as the line that crossed at right angle through the central coordinates. Each measured value was derived from the radius between a measuring point and the central axis.

3. Measuring points

For inner measuring points, they included the height 


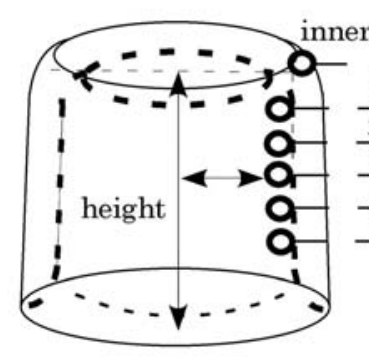

Machined crown

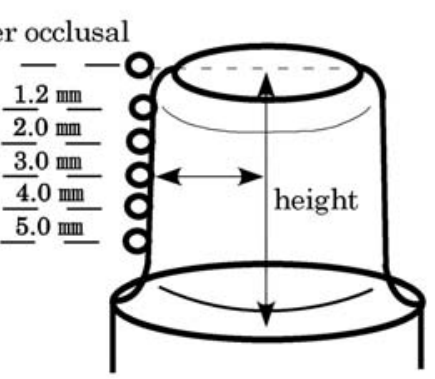

The die model

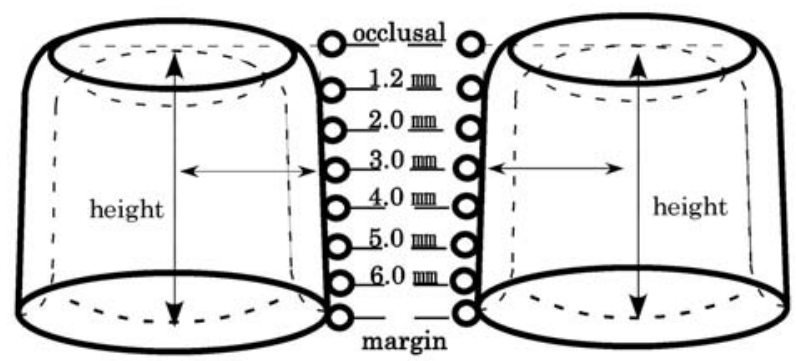

Machined crown
The crown model

Fig. 6 Inner measuring points.

Fig. 7 Outer measuring points.

Table 7 Dimensions of die and crown models

\begin{tabular}{lccccccccc}
\hline & occulusal & $1.2 \mathrm{~mm}$ & $2.0 \mathrm{~mm}$ & $3.0 \mathrm{~mm}$ & $4.0 \mathrm{~mm}$ & $5.0 \mathrm{~mm}$ & $6.0 \mathrm{~mm}$ & margin & hight \\
\hline Die model (Inner) & 3.076 & 3.164 & 3.22 & 3.292 & 3.364 & 3.435 & & & 5.945 \\
Crown model (Outer) & 3.994 & 4.085 & 4.142 & 4.215 & 4.289 & 4.365 & 4.439 & 4.506 & 7.033 \\
\hline
\end{tabular}

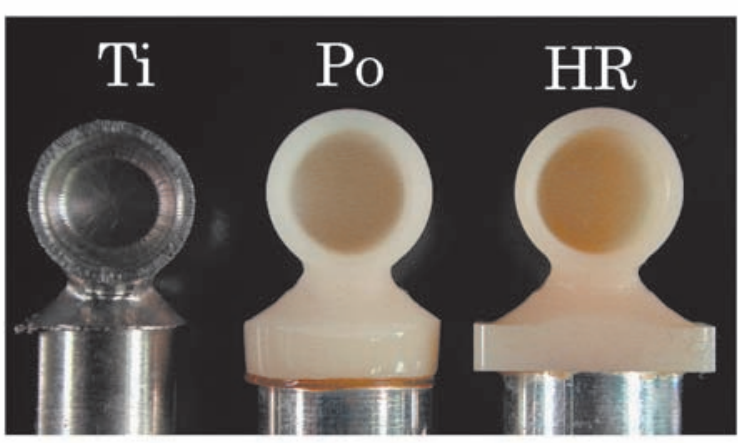

Inner crown view

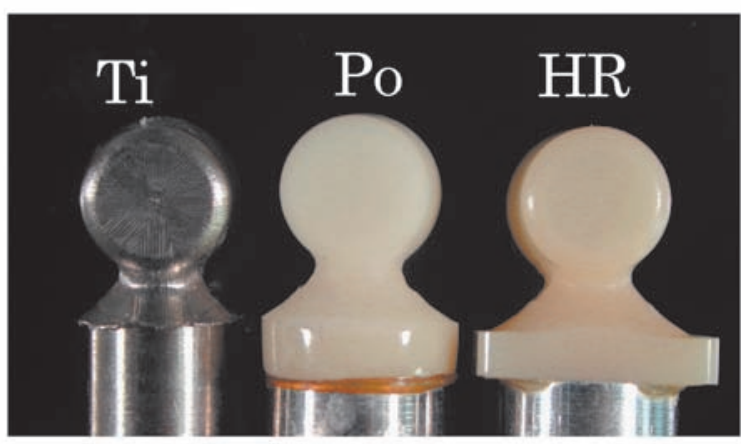

\section{Outer crown view}

Fig. 8 Inner and outer surfaces of machined crowns.

(i.e., the distance between inner occlusal and cervical area), the inner occlusal surface, and the following five points: $1.2,2.0,3.0,4.0$, and $5.0 \mathrm{~mm}$ away from the inner occlusal (Fig. 6).

For outer measuring points, they included the height, the radius of cervical area, the outer occlusal surface, and the following six points: 1.2, 2.0, 3.0, 4.0, 5.0, and $6.0 \mathrm{~mm}$ away from the outer occlusal (Fig.7). As the radius of the stylus tip was $1.0 \mathrm{~mm}$, we set it at $1.2 \mathrm{~mm}$ so that it was possible for contact measurement.

4. Measured values of die and crown models

Table 7 shows the measured values of both die and crown models using contact 3D coordinate measuring machine. Figure 8 shows the inner and outer surfaces of machinedcrowns which were used for measurement. Each measuring point was measured five times and averaged to obtain a mean, measured value.

Machining accuracy of the inner surface of a crown was obtained from deviation between the machined inner surface of a crown and the die model. In the same way, machining accuracy of the outer surface of a crown was obtained from deviation between the machined outer surface of a crown and the crown model.

After confirming that machining accuracy was equally spread out at each measuring point, two-way analysis of variance (ANOVA) was performed on the data obtained. When significant differences were noted, Fisher's multiple contrast test was carried out. A plus sign (+) indicates that a crown was machined larger than the die or crown model, and vice versa.

\section{RESULTS}

Deviation between inner surface of crown and the die model

Figure 9 shows the machining accuracy results of the inner surface of crowns and as analyzed by multiple 

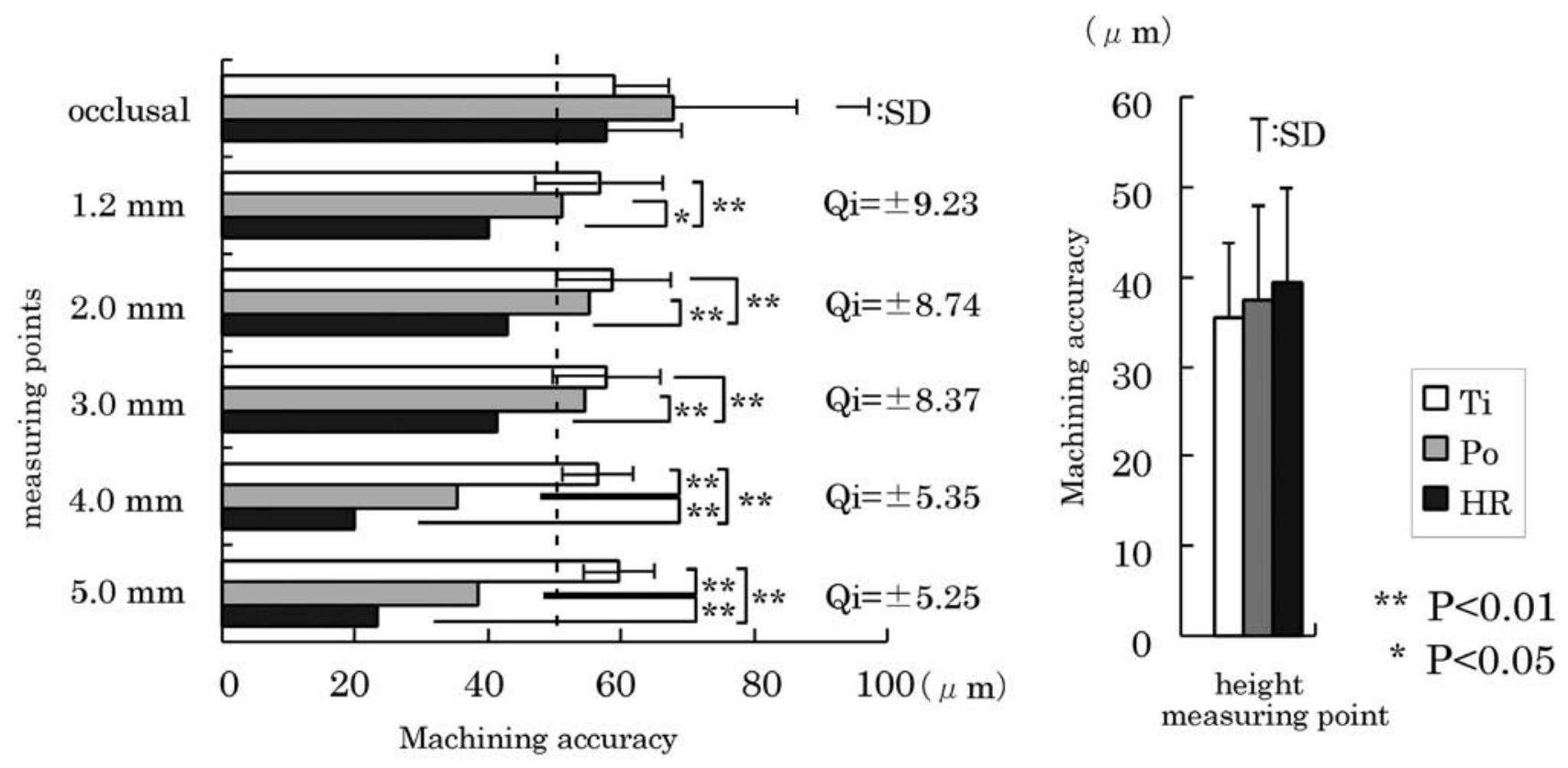

Machining accuracy affected by materials
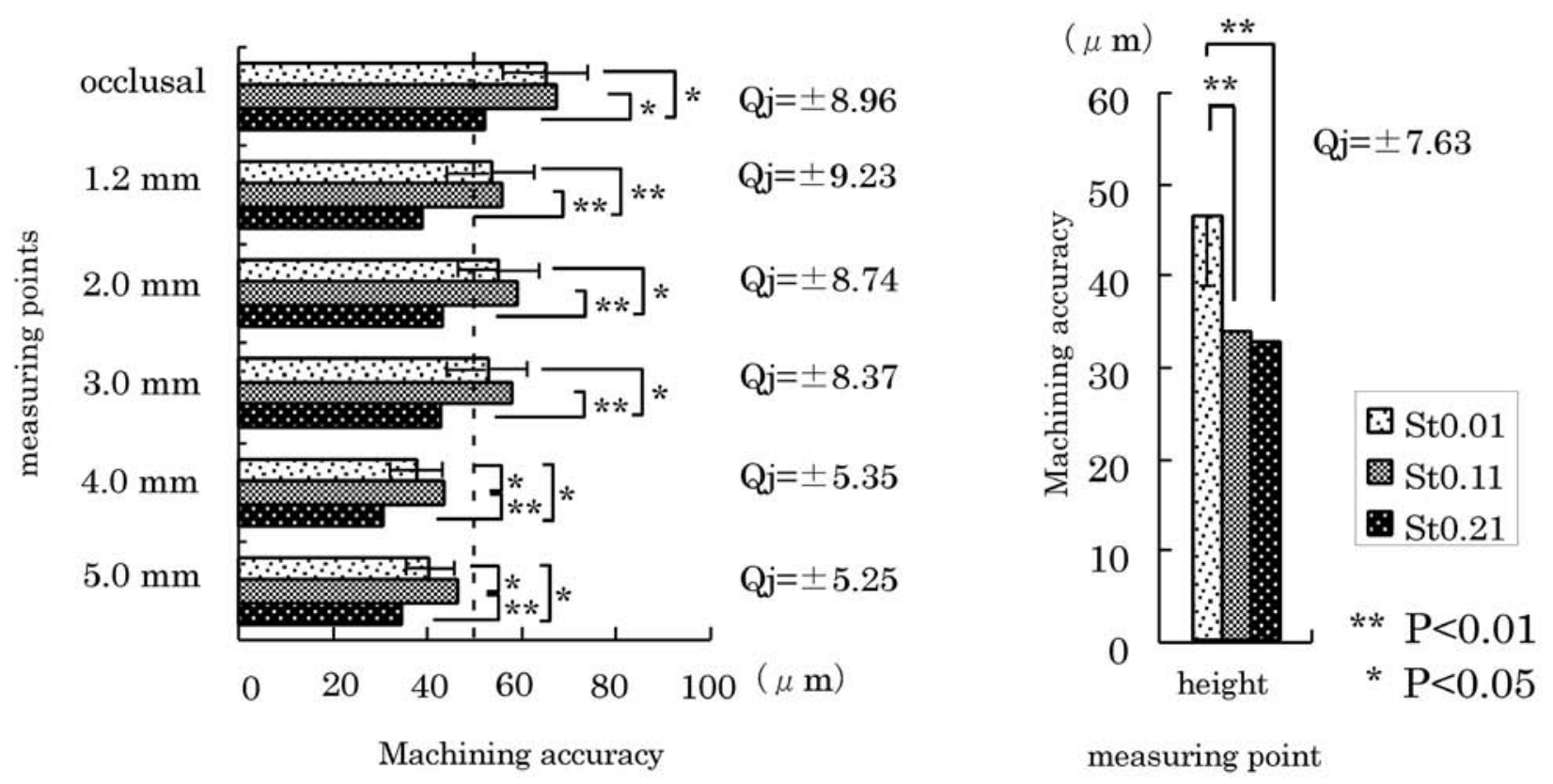

Machining accuracy affected by step-over

Fig. 9 Inner machining accuracy and multiple contrast test. 

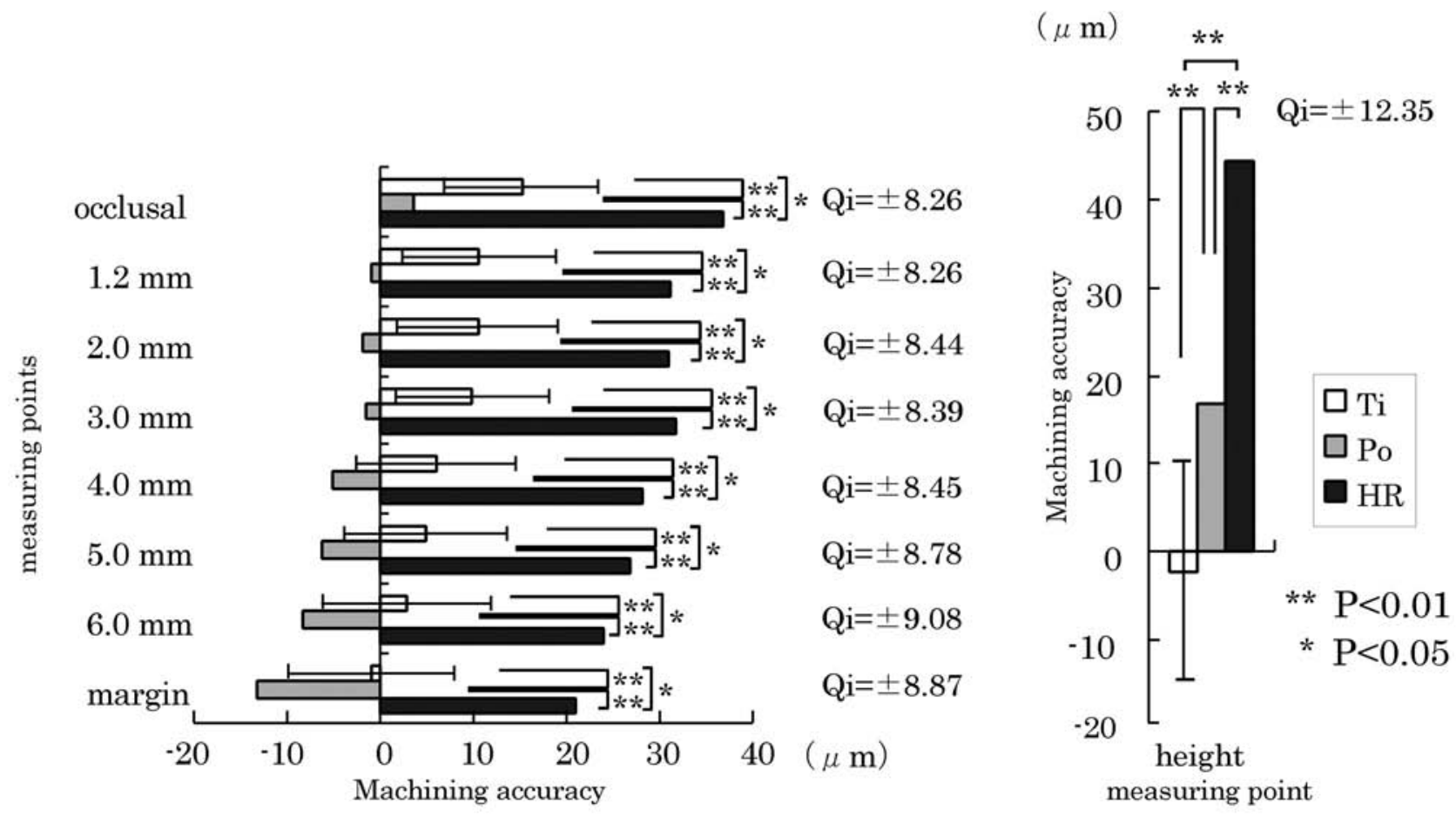

Machining accuracy affected by materials
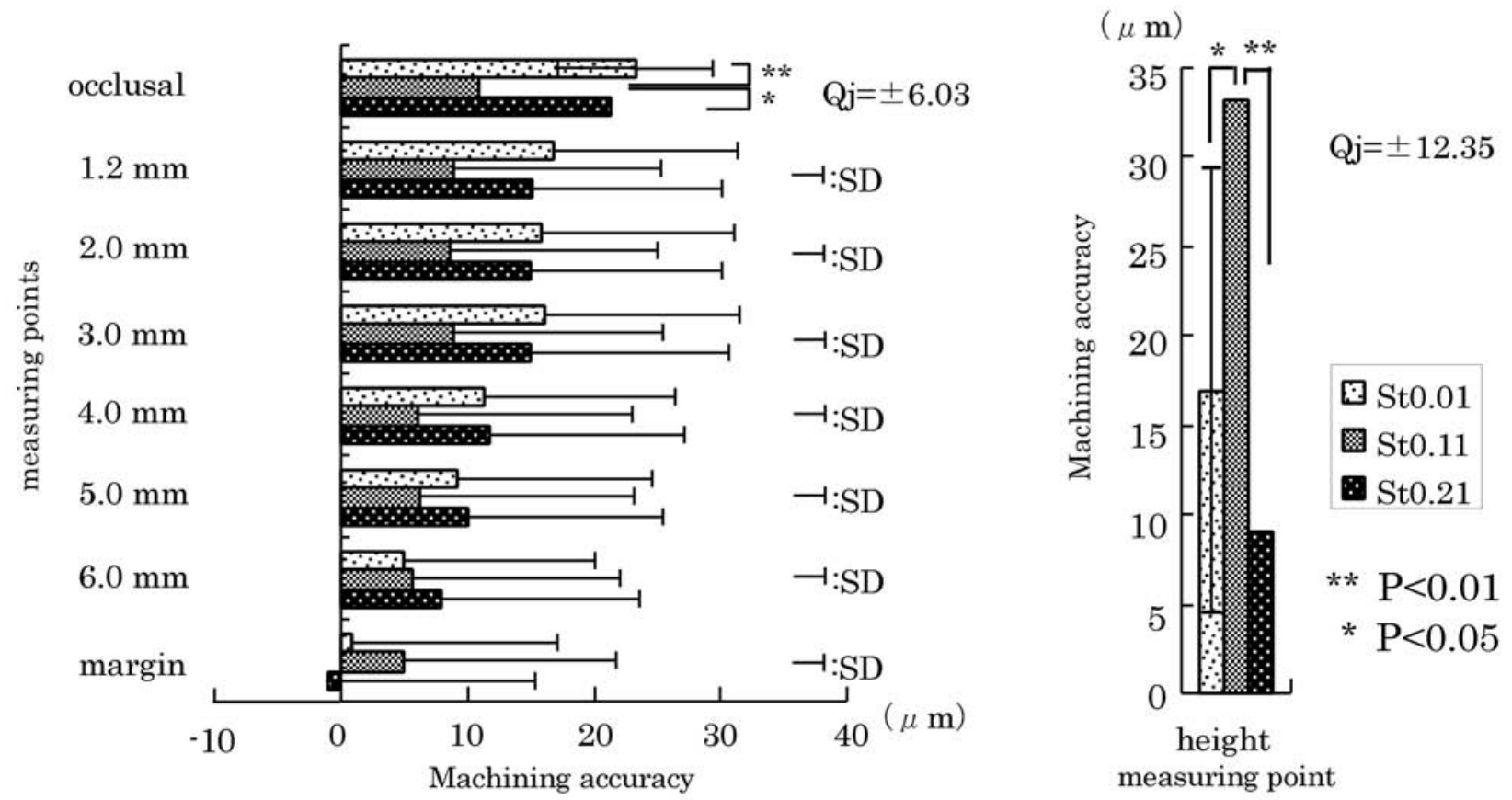

Machining accuracy affected by step-over

Fig. 10 Outer machining accuracy and multiple contrast test. 
contrast test. When examining the influence of three different CAD/CAM restorative materials on inner machining accuracy, the following were noted:

(1) At inner occlusal surface, there were no significant differences;

(2) At $1.2 \mathrm{~mm}$, significant differences were found in the descending order of $\mathrm{Ti}, \mathrm{Po}$, and $\mathrm{HR}$;

(3) At $2.0 \mathrm{~mm}, 3.0 \mathrm{~mm}, 4.0 \mathrm{~mm}$, and $5.0 \mathrm{~mm}$, significant differences were also found in the descending order of $\mathrm{Ti}$, Po and HR;

(4) With titanium, almost the same deviation of 60 $\mu \mathrm{m}$ was observed at all measuring points;

(5) With porcelain, the largest deviation of $68 \mu \mathrm{m}$ was observed at occlusal surface, then gradually decreased to $38 \mu \mathrm{m}$ at $5.0 \mathrm{~mm}$ of cervical area;

(6) With resin, the largest deviation of $58 \mu \mathrm{m}$ was observed at occlusal surface, then gradually decreased to $23 \mu \mathrm{m}$ at $5.0 \mathrm{~mm}$ of cervical area - thus showing a similar trend to porcelain;

(7) With all the three restorative materials, the inner surface was machined larger than the die model (i.e., increased gap);

(8) As for the height, deviation was in the descending order of $40 \mu \mathrm{m}(\mathrm{HR}), 39 \mu \mathrm{m}$ (Po), and $36 \mu \mathrm{m}$ (Ti), with no significant differences.

When examining the influence of step-over on inner machining accuracy, the following were noted:

(1) At occlusal surface, $1.2 \mathrm{~mm}, 2.0 \mathrm{~mm}$, and 3.0 $\mathrm{mm}$, deviations of St0.01 and St0.11 were significantly larger than that of St0.21;

(2) At $4.0 \mathrm{~mm}$ and $5.0 \mathrm{~mm}$, deviation was high in the descending order of St0.11, St0.01, and St0.21;

(3) As for the height, deviation of St0.01 was significantly larger than those of St0.21 and St0.11;

(4) St0.01 was the least spread out in deviation;

(5) In all step-over distance, deviation gradually decreased from occlusal surface to $5.0 \mathrm{~mm}$, i.e., from $65 \mu \mathrm{m}$ (occlusal surface) to $40 \mu \mathrm{m}$ (5.0 $\mathrm{mm}$ ) when scanned with St0.01, from $67 \mu \mathrm{m}$ (occlusal surface) to $47 \mu \mathrm{m} \quad(5.0 \mathrm{~mm})$ when scanned with St0.11, and from $52 \mu \mathrm{m}$ (occlusal surface $)$ to $34 \mu \mathrm{m}(5.0 \mathrm{~mm})$ when scanned with St0.21.

Deviation between outer surface of crown and the crown model

Figure 10 shows the machining accuracy results of the outer surface of crowns and as analyzed by multiple contrast test. When examining the influence of three different CAD/CAM restorative materials on outer machining accuracy, the following were noted:

(1) Significant differences were noted at all measuring points in the descending order of $\mathrm{HR}$, Ti, and Po;

(2) Deviation was largest at the occlusal surface, and gradually decreased toward the cervical area in all materials;

(3) With Ti, deviations ranged from $15 \mu \mathrm{m}$ (occlusal surface) to $-1 \mu \mathrm{m}$ (margin);

(4) With Po, deviations ranged from $2 \mu \mathrm{m}$ (occlusal surface) to $-16 \mu \mathrm{m}$ (margin);

(5) With $\mathrm{HR}$, deviations ranged from $37 \mu \mathrm{m}$ (occlusal surface) to $21 \mu \mathrm{m}$ (margin).

When examining the influence of step-over on outer machining accuracy, the following were noted:

(1) At occlusal surface, deviation of St0.11 was significantly smaller than those of St0.01 and St0.21;

(2) As for the height, deviation of St0.11 was significantly larger than those of St0.01 and St0.21;

(3) In all step-over distance, deviation gradually decreased from occlusal surface to the margin, i.e., from $23 \mu \mathrm{m}$ (occlusal surface) to $1 \mu \mathrm{m}$ (margin) when scanned with St0.01, from $11 \mu \mathrm{m}$ (occlusal surface) to $5 \mu \mathrm{m}$ (margin) when scan-

Table 8 Results of ANOVA (inner surface of crown)

\begin{tabular}{lccccccc}
\hline Measuring points & oclusal & $12 \mathrm{~mm}$ & $2.0 \mathrm{~mm}$ & $3.0 \mathrm{~mm}$ & $4.0 \mathrm{~mm}$ & $5.0 \mathrm{~mm}$ & height \\
\hline A : M aterials & non & $* *$ & $* *$ & $* *$ & $* *$ & $* *$ & non \\
B : St & $*$ & $* *$ & $* *$ & $* *$ & $* *$ & $* *$ & $* *$ \\
\hline
\end{tabular}

$* * 0.01, *<0.05$

Table 9 Results of ANOVA (outer surface of crown)

\begin{tabular}{lccccccccc}
\hline M easuring points & occlusal & $1.2 \mathrm{~mm}$ & $20 \mathrm{~mm}$ & $3.0 \mathrm{~mm}$ & $4.0 \mathrm{~mm}$ & $5.0 \mathrm{~mm}$ & $6.0 \mathrm{~mm}$ & mar gin & height \\
\hline A : M aterial s & $* *$ & $* *$ & $* *$ & $* *$ & $* *$ & $* *$ & $* *$ & $* *$ & $* *$ \\
B : St & $*$ & non & non & non & non & non & non & non & $* *$ \\
\hline
\end{tabular}

$* *<0.01, *<0.05$ 
ned with St0.11, and from $20 \mu \mathrm{m}$ (occlusal surface) to $-1 \mu \mathrm{m}$ (margin) when scanned with St0.21.

\section{Results of ANOVA}

Table 8 shows the two-way ANOVA results of the inner surface of crowns as well as the indication of significance for the different factors and interactions. Factor A (CAD/CAM restorative material) significantly affected all measuring points except for occlusal surface and height, while factor B (step-over) significantly affected all measuring points. No significant interactive effects were observed at all measuring points.

Table 9 shows the two-way ANOVA results of the outer surface of crowns as well as the indication of significance for the different factors and interactions. Factor A (CAD/CAM restorative material) significantly affected all measuring points. Factor B (step-over) significantly affected the occlusal surface and height, but not measuring points from $1.2 \mathrm{~mm}$ to the cervical area. No significant interactive effects were observed at all measuring points.

\section{DISCUSSION}

\section{Internet-based $C A D / C A M$ system}

In an internet-based CAD/CAM system, CAD and CAM are independently installed and connected via internet. To put it correctly, shapes of dental models are scanned at the dental office, whereby the captured scanning data is manipulated with a CAD program. Digitized information is then sent to the processing center, where dental restorations are fabricated and finished restorations are delivered back to the dental office.

Based on the above system setup, initial investment cost - even if the cost of upgrade option were included - is much lower than that of stand alone CAD/CAM system, as only a scanning unit needs to be purchased.

In computerized fabrication processes, the time required for scanning and data manipulation does not vary with CAD/CAM systems. On the contrary, the time required for machining varies widely with CAD/CAM systems, and it is also the most timeconsuming and costly process in computerized fabrication of restorations.

With a standalone CAD/CAM system, its indisputable advantage over an internet-based CAD/CAM system is that it can start machining immediately after the completion of scanning and data manipulation. However, its productivity per day may be limited by a longer machining time required. On the other hand, an internet-based CAD/CAM system requires time only for scanning and data manipulation.
Besides the tangible benefit of time-saving, the intangible benefit is that the personnel-at-work can obtain enough experience to become proficient because the milling of units is centralized at one place. In addition to these two advantages, high machining accuracy can be constantly achieved because system maintenance is done on a regular, scheduled basis.

Machining accuracy compared with standalone $C A D / C A M$ system

Komatsu et $a l^{5)}$ tested the machining accuracy of inner and outer surfaces (from occlusal surface to cervical area/margin) of $\mathrm{Ti}$, Po, and HR crowns using a standalone CAD/CAM system. Inner and outer machining accuracy were reported as follows: $34 \sim 31 \mu \mathrm{m}$ and $9 \sim 7 \mu \mathrm{m}$ with $\mathrm{Ti}, \quad 32 \sim 37 \mu \mathrm{m}$ and $-29 \sim-1 \mu \mathrm{m}$ with $\mathrm{Po}$, and $37 \sim 34 \mu \mathrm{m}$ and $-1 \sim-29$ $\mu \mathrm{m}$ with $\mathrm{HR}$.

This study was a similar experiment, except that an internet-based CAD/CAM system was used. Machining accuracy values of the inner and outer surfaces of $\mathrm{Ti}, \mathrm{Po}$, and $\mathrm{HR}$ crowns were as follows: 59 60 $\mu \mathrm{m}$ and 15 - $1 \mu \mathrm{m}$ with Ti, 68 35 $\mu \mathrm{m}$ and $2 \sim-16 \mu \mathrm{m}$ with $\mathrm{Po}$, and $58 \sim 20 \mu \mathrm{m}$ and $37 \sim 21 \mu \mathrm{m}$ with HR. (occlusal/margin)

As for cement film thickness, $50 \mu \mathrm{m}$ was offset in this study in the same way Komatsu et $a l^{5)}$ did in their study.

Compared with a standalone CAD/CAM system, inner crown achieved a machining accuracy which was designated for cement film thickness. Outer crowns tended to be machined smaller than the crown model (i.e., smaller crown), but their reduction rate was smaller than that of a standalone CAD/CAM system, showing higher machining accuracy.

\section{Influence of step-over}

At almost all measuring points on the inner crown surface, St0.01 and St0.11 significantly affected machining accuracy as compared with St0.21. As for the machining accuracy of the outer surface of crowns, no significant differences were found at almost all measuring points. In particular, St0.11 achieved the highest machining accuracy around the cervical area.

To meet the demand for high-precision machining, rigorous scanning accuracy is required. In the case of Cadim, CAD data was processed by connecting each digitized point with a straight line. Therefore, as shown in Fig. 11, when a large stepover distance was used, slightly more inward-oriented machining was done due to smaller data volume, thus fabricating significantly smaller crowns when compared with smaller step-over distances.

When comparing the inner and outer surfaces of 


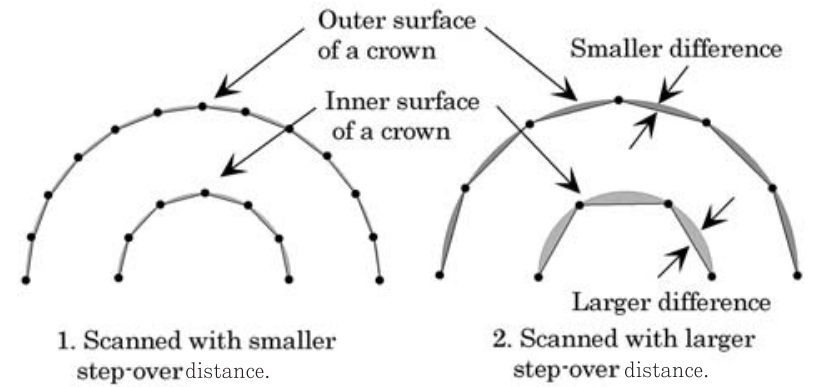

Fig. 11 Relation between data volume and machining accuracy.

a crown, inner surface with a smaller radius is more susceptible to be influenced by step-over. This was probably why significant differences were observed at the inner surface of crowns, but not so at the outer surface.

At the measuring points of $4.0 \mathrm{~mm}$ and $5.0 \mathrm{~mm}$ of inner crown, St0.11 achieved the most accurate machining despite high-precision scanning of St0.01. Scanning noise increases in proportion to measurement accuracy. When machining based on captured scanning data varies among scanning points, higher scanning points are automatically recognized to enable machining of a $\varphi 1 \mathrm{~mm}$ tool.

To eliminate over-machining, Cadim automatically recognizes digitized points, which allow minimum machining. This could be a key reason why the amount of machining was reduced.

Considering the interaction of machining accuracy, scanning time required, and data volume, the authors have come to a conclusion that St0.11 was an optimal scanning condition.

\section{Clinical application}

Nakamura et $a l .{ }^{13)}$ reported that a cementing medium of even film thickness was critical to high bond strength. In the case of ceramometal crowns, Konishi et al. ${ }^{12)}$ advocated a $15-\mu \mathrm{m}$ film thickness at cervical area and $20 \sim 50 \mu \mathrm{m}$ for the remaining area. On the other hand, Yoshida ${ }^{14)}$ suggested a film thickness of $40 \sim 70 \mu \mathrm{m}$, but that it gradually decreased to a minimal film thickness at cervical area. In this study, mean machining accuracy of inner titanium crowns was approximately $60 \mu \mathrm{m}$ at all measuring points, which was consistent with the recommendation by Yoshida ${ }^{14)}$. With porcelain and resin, cement film thicknesses were approximately $38 \sim 68 \mu \mathrm{m}$ and 20 58 $\mu \mathrm{m}$, respectively.

Beschnidt and Strub ${ }^{15}$ reported that the mean marginal adaptation of all ceramic crowns fabricated with porcelain-fused-to-metal method was $47 \sim 99 \mu \mathrm{m}$. In this study, the following mean machining accuracies at the cervical area were obtained: $-1 \mu \mathrm{m}$ (titanium), $-13 \mu \mathrm{m}$ (porcelain), and $21 \mu \mathrm{m}$ (resin).
Clinically acceptable marginal fit of a crown is reported to be $100 \sim 200 \mu \mathrm{m}^{16,17)}$. In light of this clinically acceptable range, the CAD/CAM crowns fabricated in this study were considered clinically safe and applicable ${ }^{18-24}$.

\section{CONCLUSIONS}

To investigate if accurate crowns could be fabricated efficiently using an internet-based CAD/CAM system, this study was carried out with three different step-over scanning distances $(0.01 \mathrm{~mm}, 0.11$ $\mathrm{mm}$, and $0.21 \mathrm{~mm}$ ) and three different CAD/CAM restorative materials (Ti, Po, and HR). Results were then compared to determine the optimal scanning condition. Within the limitation of this study, the following conclusions were drawn:

(1) When examining the influence of three different $\mathrm{CAD} / \mathrm{CAM}$ restorative materials on inner machining accuracy from occlusal surface to $5.0 \mathrm{~mm}$, the following deviation values were obtained: $60 \mu \mathrm{m}$ with $\mathrm{Ti}$, range of $68 \mu \mathrm{m}$ to 35 $\mu \mathrm{m}$ with $\mathrm{Po}$, and range of $58 \mu \mathrm{m}$ to $20 \mu \mathrm{m}$ with HR.

As for outer machining accuracy from occlusal surface to margin, deviation ranged from $15 \mu \mathrm{m}$ to $-0.7 \mu \mathrm{m}$ with Ti, from $2.3 \mu \mathrm{m}$ to $-15.7 \mu \mathrm{m}$ with $\mathrm{Po}$, and from $36.7 \mu \mathrm{m}$ to $21 \mu \mathrm{m}$ with HR.

Deviation of both inner and outer surfaces of crowns gradually decreased from occlusal surface to cervical area, except for the inner surface of Ti crown.

(2) When examining the influence of step-over on inner machining accuracy, deviations of St0.01 and St0.11 were significantly larger than that of St0.21 from occlusal surface to $3.0 \mathrm{~mm}$. At $4.0 \mathrm{~mm}$ and $5.0 \mathrm{~mm}$, deviation was high in the descending order of St0.11, St0.01, and St0.21.

As for outer machining accuracy, no significant differences were observed from $1.2 \mathrm{~mm}$ to cervical area.

In all step-over distances, deviation gradually decreased from occlusal surface to cervical area.

(3) Height was machined larger than the die or crown model in all conditions, except for titanium outer surface.

The present study revealed that the inner surface was machined larger than the die model, whereas the outer surface of porcelain crown was machined smaller than the crown model. Considering the interactions of machining accuracy, scanning time required, and data volume, the authors have come to a conclusion that St0.11 was an optimal scanning condition. 


\section{REFERENCES}

1) Matsuda T, Shin-ya A, Tomita S, Shin-ya A, Mitobe $\mathrm{T}$, Hasebe $\mathrm{S}$, et al. A clinical report and a small study of fitness on Procera AllCeram crown. J J Prosthondont Soc 2004; 48: 543-548.

2) Milleding P, Haag P, Neroth B, Renz I. Two years of clinical experience with Procera titanium crowns. Int J Prosthodont 1998; 11(3): 224-232.

3) Shirai M, Shin-ya A, Yokozuka S. Inner surface working accuracy of titanium crowns milled with CAD/CAM. J J Prosthodont Soc 1999; 43(1): 160-170.

4) Ito M, Shin-ya A, Yokozuka S. Working accuracy of CAD/CAM crown restorations with material cuts. J J Prosthodont Soc 1999; 43(3): 614-625.

5) Komatsu H, Shin-ya A, Gomi H, Shin-ya A, Yokoyama D. Machining accuracy of CAD/CAM crown using various restorative materials. J Jap Soc Dent Products 2007; 21(1): 26-36.

6) Sohmura T, Takahashi J. Use of CAD/CAM system to fabricate dental prostheses. Part 1: CAD for a clinical crown restoration. Int J Prosthodont 1995; 8(3): 252-258.

7) Hikita K, Maeda T, Kobayashi K, Tanaka O, Fujii T, Ohno $\mathrm{H}$, et al. Marginal fitness of composite resin crown fabricated by the dental CAD/CAM system. J J Dent Mater 2002; 5: 294-301.

8) Takeuchi Y, Shin-ya A, Matsuda T, Tomita S. Time course working accuracy of CAD/CAM titanium crowns restoration with repeat cutting - Durability of tungsten carbide burs. J J Dent Equip 2003; 9: 2635.

9) Hotta Y, Miyazaki T, Fujiwara T, Tomita S, Shin-ya A, Sugai $\mathrm{Y}$, et al. Durability of tungsten carbide burs for the fabrication of titanium crowns using dental CAD/CAM. Dent Mater J 2004; 23(2): 190-196.

10) Tomita S, Shin-ya A, Gomi H, Matsuda T, Ogura H, Miyazaki T, et al. Machining accuracy of CAD/CAM ceramic crowns fabricated with repeated machining using the same diamond bur. Dent Mater J 2005; 24(1): 123-133.

11) Yara A, Ogura H, Shin-ya A, Tomita S, Miyazaki T, Sugai Y, et al. Durability of diamond burs for the fabrication of ceramic crowns using dental
CAD/CAM. Dent Mater J 2005; 24(1): 134-139.

12) Konishi M, Watanabe K, Yokozuka S. Inner surface form changes of the cast crown using gypsum-bonded investments. J J Prosthodont Soc 1985; 29(4): 103-120.

13) Nakamura K, Ono Y, Morita K. Our views on restorations fitness and systematic clinical procedures. Practice in Prosthodontics 1987; 20: 673-690.

14) Yoshida K. Practical accuracy of the casting method in dentistry. J J Prosthodont Soc 1958; 2: 159-190.

15) Beschnidt SM, Strub JR. Evaluation of the marginal accuracy of different all-ceramic crown systems after simulation in the artificial mouth. J Oral Rehabil 1999; 26: 582-593.

16) Karlsson S. The fit of Procera titanium crowns. An in vitro and clinical study. Acta Odontol Scand 1993; 51: 129-134.

17) Boening KW, Walter MH, Reppel PD. Non-cast titanium restorations in fixed prosthodontics. J Oral Rehabil 1992; 19: 281-287.

18) Gorman CM, McDevitt WE, Hill RG. Comparison of two heat-pressed all-ceramic dental materials. Dent Mater 2000; 16: 389-395.

19) De Jager N, Feilzer AJ, Davidson CL. The influence of surface roughness on porcelain strength. Dent Mater 2000; 16: 381-388.

20) Odman P, Andersson B. Procera AllCeram crowns followed for 5 to 10.5 years: A prospective clinical study. Int J Prosthodont 2001; 14: 504-509.

21) Ukon S, Ishikawa M, Tohyama M, Sato H. Determination of fabricating conditions for the preferable marginal and internal adaptation of the mica crystal castable ceramic crown. Dent Mater J 2004; 23: 53-62.

22) Okamura M, Chen KK, Kakigawa H, Kozono Y. Application of alumina coping to porcelain laminate veneered crown. Part 1: Masking ability for discolored teeth. Dent Mater J 2004; 23: 180-183.

23) Jin J, Takahashi H, Iwasaki N. Effect of test method on flexural strength of recent dental ceramics. Dent Mater J 2004; 23: 490-496.

24) De Jager N, Pallav P, Feilzer AJ. The influence of design parameters on the FEA-determined stress distribution in CAD-CAM produced all-ceramic dental crowns. Dent Mater 2005; 21: 242-251. 